creased in bulk. The iodide of iron, and all aperients, have been discontinued, the bowels having lately acted with regularity. The use of opiates has been greatly diminished by enema, and in ternally altogether omitted. The sickness and other gastric inconveniences have ceased ; the irritation in the rectum and neck of the bladder are no longer complained of ; quietude has succeeded to irritability of the nervous system. 11th.-Comfortable, and opiates greatly diminished; other medicines unnecessary. Been in the garden on a sofa cushion. 21st.-Reports favourably. Opiate reduced to a very small dose. Walked to the Haven, with no uneasy effects. Oct. 8th.-Can walk two miles and a half. Opiates discontinued. At first the nights were bad. Last night she slept well, having taken a quantity of brandy and water. No irritation at the neck of the bladder. Some pressure still on rectum, otherwise feels well. Bowels regular.

Dec. 6th.-Again carefully examined the uterus, which is less fixed. The retroversion continues, the fundus still extending towards the sacrum, while the os uteri approaches the pubes. The two membranous pendicles remain hanging out of the os uteri. The health quite good, and the catamenia regular; the nervous pains and irritations all subsided. Renewed habits of activity seem to have greatly contributed to restore the symmetry of the abdomen.

A glance at the prescriptions employed, excepting on particular emergencies, during the last three years, will shew the error of supposing that Miss M. was in the habit of seeking relief in large and unmeasured doses of opium. (It is unnecessary to copy them in this analysis.)

Knowing well that no malignant disease of the affected organ existed, I always believed that a time would arrive when my patient would be relieved from most of her distressing symptoms, and released from her long. continued confinement. The catamenial crisis appeared the most probable period, but I did not despair of this happening sooner; though she never willingly listened to my suggestions of the probability of such events, but seemed always best satisfied with admissions that she must ever remain a secluded invalid-an additional symptom of the morbid influence over the nervous system, of the class of diseases in which this case must be included. Oftener than once $I$ have used the expression that, probably, before long, Miss M. would take up her bed and walk. In this case the advocates of mesmerism may try to find arguments in support of their opinions. But the experienced practitioner will have little difficulty in bringing the whole into harmony with the well-established laws of human physiology. The condition of the uterus in December, 1844, is but the natural sequel of progressive improvement begun in April ; and the time had arrived when a new and powerful stimulus only was required, to enable the enthusiastic mind of my patient to shake off the nervous symptoms.

\section{THE GOVERNMENT MEDICAL BILL.}

\section{MEETINGS OF THE MEDICAL PROFESSION.}

\section{FINSBURY.}

ON Saturday night a large and influential meeting of the general practitioners residing in the borough of Finsbury, was held at the Freemasons' Tavern, to take into consideration the best means of opposing Sir James Graham's Medical Profession Bill-Mr. Chrfton, of Islington, was unanimously elected to the chair.

The Charrmas opened the business of the evening. $\mathrm{He}$ was sure there would be a perfect unanimity of feeling among all present. The circumstances were most important which had called them together. Within the last thirty years the status of the general practitioner had been greatly improved by his own exertions. 'The general practitioners, it would seem, had been raised to their high position only for the purpose of an attempt being made to crush them. There seemed to be a conspiracy among certain parties to sacrifice them; but they were not to be easily crushed. The general practitioners had done much for the cause of humanity. They had arrested the progress of that scourge of the human race, the small-pox. The reward they had met with for their humanity was to degrade them by reducing their charge for vaccination to eighteenpence. He could not but express the strongest feeling of indignation at the conduct of the College of Surgeons. They had seriously injured the character and lowered the status of the general practitioner; and yet the general practitioners were on a footing of perfect equality as regarded professional knowledge and skiil with the council of the College of Surgeons. (Applause.) The conduct of that body was a virtual robbery; for they had received the money of the general practitioners, while they, by their recent proceedings, stripped them of their rights. Still more calculated to degrade and annihilate the medical profession was the Bill now before the legislature. (Hear, hear.) He trusted there would be a feeling of entire cordiality and unanimity among them. He believed sincerely that if this Bill were carried into a law, it would not only give a serious blow to the medical profession, but would prove most injurious to the best interests of society. He trusted they would shew, by their energy and determination, that they would not be crushed, but would deprive Sir James Graham of the pleasure of being cheated even though he seemed to be most desirous to cheat. (Loud cheering.)

Mr. Hrulrer rose to move the first resolution. Their chairman had ably stated the circumstances under which they had assembled. He would, therefore, at once read the resolution which had been intrusted to him; the resolution was-

" That in the opinion of this meeting any legislative enactment for the regulation of medical and surgical practice should afford the utmost possible protection to the public against ignorant and unqualified practitioners, and should maintain the just rights and interests of those who have proved by competent examination their fitness to undertake the important duties of their profession."

He was sure all would concur in the propriety of adopting this resolution. Should the Bill of Sir James Graham pass into a law, they might all take up their hats and seek some other mode of earning a livelihood. It would be entirely destructive of the general practitioner. The speaker then proceeded at some length to point out the circumstances under which the general practitioners had attained their present high position. He therefore trusted that they would oppose that measure with the utmost determination, but at the same time in a gentlemanly manner. If they so opposed it, he had no doubt they would succeed in their efforts; for he had the best reason for believing that the legislature was disposed to listen to their representations. $\mathbf{M r}$. Hillier then sat down amidst cheers.

Mr. Saner seconded the resolution. He had been in practice for fifty years, and the Bill would not affect him personally. $\mathrm{He}$ resisted it, however, from a full conviction of the evils that would result from throwing open the profession; and he mentioned the case of a tinker who, previously to 1815 , established himself in general practice. The resolution was then put and carried unanimously.

Mr. Hunter proposed the second resolution, and proceeded to analyze the leading provisions of the Bill. That Bill proceeded on a wholesale scale of repeal. It proceeded to repeal all the laws which had been passed relative to the medical profession from the time of Henry VIII. down to the year 1815. By one stroke of the pen eleven different acts of the legislature were entirely cancelled. The effect of the Bill would be to let loose on the country a host of unqualified men, who would thus be put on the same footing as the regularly educated gentlemen who composed that meeting. The registry of qualified men would practically be a nullity, for ignorant people would never take the trouble to examine as to who were regular practitioners and who were not. It was just the same as if Sir James Graham were to repeal all the excise laws, and then publish a list of those who were licensed to distil or sell spirits; telling the public they vould be able by that list to distinguish between those who were legitimate dealers and those who were smugglers. 'The Bill would open a door to 30,000 chemists, who were ready to start as practitioners the moment they had an opportunity. They would also have an extensive importation of Germans, and Americans, aye, "Doctors" from all countries. (A laugh.) The result of ignorant persons practising as medical men would be not only that thousands of the community would lose their health and their limbs, but their lives also. (Hear, hear.) The conduct of Sir James Graham was most censurable in relation to the mode in which he had brought it before the legislature. There was a flippancy in his manner most discreditable to a home secretary of such a country as England. It was difficult to understand the feelings of any man who could so introduce a measure in which the interests of the whole community were so seriously involved. He quoted, in a manner which could not be sufficiently censured, the well-known lines-

\section{"Doubtless the pleasure is as great
Of being cheated as to cheat."}

He would like to know what pleasure Sir James Grabam could himself enjoy from being cheated by some quack doctor, who, by his empiricism, subjected him to the most excruciating torture. If this Bill passed, any man might with impunity kill as many persons as he pleased by his unskilful medical treatment. Should the Bill pass, no respectable man would think of bringing up his son to the medical profession. (Hear, hear.) Mr. Hunter concluded by moving the following resolution, namely :- 
"That this meeting has experienced much disappointment that a Bill presented to the Commons House of Parliament by one of her Majesty's Secretaries of State, and professing to regulate the practice of medicine and surgery, should be so manifestly inadequate to secure either the safety of the public or the respectability and scientific education of the medical profession; and is convinced, that should the proposed measure become law, it would sanction the practice of the ignorant and uneducated, and expose the regular practitioner to a degrading competition with the empiric." (Loud cheers.)

Mr. Brodribs seconded the resolution. In referring to the acquittal of an unlicensed practitioner who had used arsenic externally in the cure of cancer, he read an extract from a lecture by Sir B. Brodie: the moment the name of that gentleman was mentioned there was a general hissing and expression of disapprobation from the meeting. If this Bill passed into a law, (said $\mathrm{Mr}$. B.) the country would be overrun with ignorance and presumption. The celebrated Mr. Abernethy once asked, in his hearing, a young man, who had come up from the country to attend Bartholomew's Hospital, how long he meant to study the medical profession. The young man replied, "Six months." "Then," said Mr. Abernethy, with that singularly significant look which he could so well give, and which those who witnessed it never could forget,-- " then, sir, the Lord have mercy on your patients." (Loud laughter.) The Bill of Sir J. Graham seemed framed for the special purpose of encouraging and protecting quacks of every kind.

Mr. WhIte, before the resolution was put, wished to say a few words. Sir J. Graham was no more the author of the Bill than their chairman. They knew who were the authors of the measure. (Cries of "Name, name.") They were well known, and they ought to be marked men. Let the general practitioners determine that they would never call in any of the authors of the measure to any consultation. (Loud applause.) That was the way to punish them. They deserved to be execrated by the general practitioner. (Loud cheers.)

After a few observations from Mr. Davies, Mr. Streeter questioned the right of the Crown to grant a charter like that lately given to the college. The vested rights of individuals could not be interfered with, unless the Houses of Parliament sanctioned the proceeding. The resolution was carried unanimously.

Mr. VAN Oven moved the third resolution, which was-

"That as to the constitution of the proposed Council of Health, the omission of the general practitioner appears to this meeting not only inexpedient but unjust towards that branch of the profession which must necessarily be intrusted with the management of a large majority of the most important diseases; and it cannot, therefore, afford any security that the public interests will be duly regarded."

Putting the medical profession entirely out of the question, the interests of the community were deeply affected by the Bill. It would be most destructive, not only of the health and the lives of the community, but it was positively cruel and inhuman to the lower and more ignorant members of society, for they could not be expected to go about in quest of the registry to see whether the name of a particular person was in the list. (Cheers.) $\mathrm{He}$ would ask, was it possible that such a measure as this could be considered by any intelligent man as one for the improvement of the medical profession? If the members of the legislature had the slightest regard for their wives and families, they would at once protect the public from uneducated men. The Greneral Council of Health was altogether inefficient, and only the puppets for the Secretary of State for the time being; they were to be nominated by the Crown, and sit for three years. The result of such a measure must degrade the profession; members would leave it with disgust-no person of the least laudable ambition would place his son in a profession which would only degrade him-and the profession must eventually be recruited from the ranks of uneducated and ignorant pretenders.

The resolution was seconded by Mr. Husren, jun., and carried unanimously.

The fourth resolution was proposed by Mr. RANDALI; it was as follows :-

"That the exclusion of the general practitioner from the Council of Health would render his admission to the Court of Examiners little better than nominal ; for, absolutely denying him a voice in the arrangements of medical studies, and depriving him of the power to determine either the character or degree of the examination of candidates, it would necessarily place him on an unequal footing with his proposed colleagues. To an arrangement so prejudicial to the public, and so subversive of the interests of the largest portion of the profession, this meeting decidedly objects, for the reasons following:-First, because the professional education of the general practitioner will be better arranged by members of his own body than by individuals of any other class. Second, because the experience of the last thirty years affords an illustration of his capability to discharge advantageously to the public all the duties devolving on him. Third, because the present standard of professional qualification is to be traced to the regulations and examinations which have been adopted, and have materially aided in securing to the general practitioner his present useful and honourable position."

The resolution was seconded by Mr. Mrres, who took the same view of the Bill as the former speakers; and stated, that the health of the community was of the utmost and of paramount importance, and required great exercise of medical skill, which the proposed Bill would totally destroy, only favouring the ignorant pretender. The speaker, in a very argumentative speech, pointed out to the meeting the very great reason that the profession should adopt decisive measures against the toleration of unlicensed men.

Several gentlemen afterwards spoke at great length from the body of the meeting, deprecating the whole of the clauses of the Bill; and said, it would only have the effect of rendering the medical students indifferent whether they qualified themselves or not. What would become of the Council of Health if the cholera broke out in the metropolis? What could her Majesty's Secretary of State know about the treatment of cholera? And would the five Regius Professors of Medicine of the universities come to London to stay its progress? Whom would the public naturally look up to but the general practitioners, who were the most numerous branch of their profession, and would be regarded by the public as the only men to whom they could look forward with confidence at such a crisis?

The resolution was put and carried in the midst of great cheering.

The fifth resolution was proposed by Mr. Powedx-

"That this meeting cordially concur's in the establishment of an effective system of registration, but considers it a necessary accompaniment of, rather than a substitute for, a salutary legal restriction, since the safety of the public will be more decidedly insured by the positive prohibition of the incompetent, than by a dependence on a registration of the authorized and efficient."

It was seconded by Mr. Couplis, and carried.

The sixth resolution was moved by Mr. R. H. Semple, and seconded by Mr. Courtenay-

"That a Medical Association for the borough of Finsbury be formed, to watch the proceedings in Parliament, in connexion with the interests of the medical public, to co-operate with the executive of the Society of Apothecaries, and with other associations, in their endeavour to obtain a charter of incorporation for the general practitioner in medicine and surgery, to prepare a petition to Parliament, and to adopt such other measures as may be best calculated to promote the usefulness and respectability of this branch of the profession; and that the following gentlemen be requested to lend their valuable services in furthering these important objects-viz.,

\section{President-N. Cliffon, Esq.}

COMMITTEE.

J. M. Camplin, Esq. J. Courtenay, Esq.

H. Combe, Esq.

H. B. Hillier, Esq.

J. Hunter, Esq.

J. Jeaffreson, Esq.

J. Miles, Esq.

R. Farrants, Esq W. Fortesque, Esq J. Fullarton, Esq.

W. Garlike, Esq. J. Harding, Esq.

A. M. Randall, Esq. J. Highett, Esq.

J. Saner, Esq.

B. Van Oven, Esq.

J. F. Austin, Esq.

R. Brett, Esq.

R. Brien, Esq.

W. P. Brodribb, Esq

J. Brown, Esq.

N. H. Clifton, Esq.

J. Hunt

F. Ingoldby, Esq.

J. Ireland, Esq.

J. Jeafferson, jun. Esq

B. Phillipps, Esq.

H. Powell, Esq

J. C. Powell, Esq

J. M. Ramsbotham Esq.

H. P. Ree, Esq.

S. Reynolds, Esq

S. Richards, Esq.

C. Ridley, Esq.

W. H. Semple, Esq

W. B. Kesteven, Esq. S. Stedman, Esq.

Lambert, Eso

O. Law, Esq

F. Mosgrove, Esq.

W. Taylor, Esq.

F. Wood, Esq.

\section{$\left.\begin{array}{l}\text { H. C. Harris, } \\ \text { H. James, }\end{array}\right\}$ Hon. Secs.}

The serenth resolution was moved by Mr. C. LAw, and seconded by Mr. Riceardos-

"That this meeting hereby expresses its grateful sense of the able manner in which the provisions of the Act of 1815 have been carried into effect by the Worshipful Society of Apothecaries."

The eighth resolution was moved by $\mathrm{Mr}$. H. Comse, and seconded by Mr. N. Clifron, jun.-

"That this meeting further acknowledges with gratitude the eminent talent and great zeal which have been recently displayed in The Times newspaper, THE LANCET, and other public joumals, in the cause of medical reform." 
The ninth resolution was moved by Mr. H. C. Harris, and seconded by Mr. H. JAMES-

"That a subscription be opened to defray the expenses necessarily incurred in the proceedings of this Association." Signed, N. Chifton, Chairman.

It was moved by Mr. A. M. RANDALL, and seconded by Mr. B. VAN Oven-

"That the thanks of this meeting are due, and are hereby presented, to N. Clifton, Esq., for his able and obliging conduct in the chair."-Carried by acclamation.

A subscription was entered into, and the meeting separated.

\section{MEDICAI, AND SURGICAL ASSOCIATION OF THE} BOROUGH OF ST. MARYLEBONE.

A meeting of this Association was held on Monday evening last, when the following resolutions were unanimously adopted, - John Propert, Esq., V. P., in the chair.

The Cramanas stated that they met this evening to perform a painful, though at the same time a pleasing duty: it was in this room that the first effort was made by general practitioners to shake off the yoke of oppression endeavoured to be fastened on them by the College of Surgeors and the Government of the country, and they again returned to the same place, pleased with the result of their labours, which had proved so successful, in order to effect its union with the National Association of General Practitioners; the plans put forth in the "Marylebone Manifesto," which had already effected so much good throughout the country, had been proposed here, and formed the basis of organization of the general practitioners. After further remarks the following resolution was proposed by Mr. Brown, seconded by Mr. Cocke, and passed unanimously:-

"That the Medical and Surgical Association of the Borough of Marylebone do merge into the 'National Association of General Practitioners in Medicine, Surgery, and Midwifery,' instituted at a public meeting, held at the Hanover-square Rooms, on the 7th of December, under the presidency of $\mathrm{Mr}$. Pennington."

After a lengthened discussion, participated in by Mr. Gray, Mr. Barker, Mr. Craddock, Mr. Ancell, Mr. Brown, Mr. O'Connor, and Mr. Squibb, it was proposed by Mr. BARKer, seconded by Mr. Claxtox, and passed-

"That the foregoing resolution be advertised in three of the

London morning papers, and in Tre LANCET and Medical Gazette of this week."

It was proposed by Mr. VICKERs, seconded by Mr. WEBsTER, and passed unanimously -

"That the treasurer and honorary secretary be requested to confer with the official agent of the 'National Association of General Practitioners in Medicine, Surgery, and Midwifery,' for the purpose of enrolling those names which are not already entered in the books of that association."

It was proposed by Mr. SQuibr, seconded by Mr. Propert, and passed-

"That the cordial thanks of this association be given to $\mathrm{Mr}$. O'Connor, for his able conduct as hon. secretary, and that some substantial mark of respect to the extent of the subscriptions be conveyed to him."

It was proposed by Mr. Axcell, and seconded by Mr. BARKER-

" That the treasurer do take charge of the books of this association, and keep them in existence as long as he thinks proper."

Votes of thanks were also passed to the president, vice-presidents, and treasurer, when the meeting separated.

\section{HOSPITAL REPORTS.}

\section{ROYAL LONDON OPHTHALMIC HOSPITAL.}

ptosis.-(Palsy of the thiRd paIr of Nerves; PUPIL DILATED AND INACTIVE; UPPER OBLIQUE AND OUTER RECTUS UNAFFECTED.)

Case 1. - R. C-_, aged fifty-six, a stout-built man, but of pallid features, applied as an out-patient, under Mr. Scott, Sept. 26th, for the relief of dropping of the right upper eyelid. There was complete palsy of the superior palpebra, so that he was compelled to raise it with his finger if he wished to observe any object; pupil so dilated as to reduce the breadth of the iris to about a line and a half; vision slightly impaired; diplopia existing, except when the axis of the left eye corresponded to that of the right. The ball itself was directed downwards and out-

wards. He complained of pain in the right side of the temple. The tongue furred; pulse full and hard. He attributes the affection to a severe cold which he caught about twelve days prior to his present application. He was prescribed for as follows:To be cupped to ten ounces on the left temple. A grain of calomel every hour.

On his second application, Oct. 6, the gums ware very sore, and he had profuse salivation. He had obtained slight power over the eyelid, so that he could expose about a line's breadth of the cornea. The mercury was omitted, and he was ordered to take a little sulphate of magnesia and dilute sulphuric acid three times a day, and to gargle his mouth out frequently with diluted chloride of lime. On the $13 \mathrm{th}$, the palpebra could, without much effort, be raised so as to expose the lower half of the cornea; and there was slight tremulous action of the other muscles supplied by the third pair, with the exception of the iris, which still appeared passive.

Oct. 31.-Axis of the eye directed forwards; pupil less dilated than before; raises the palpebra, so as to expose all but a line of the cornea.

PARTIAL PTOSIS.

Case 2. - J. M-, aged forty-two, a chemist by trade, and of sallow complexion, came under the care of Mr. Scott, Aug. 11. The right eye was affected. The upper palpebra could be elevated to only about half its usual extent. There existed double vision of near and remote objects, particularly when the upper rectus, which was partially palsied, was called into action; partial inactivity of the inner rectus, and a slightly downwards and outward direction of the axis of the eye; marked inactivity of the iris, less dilated, however, than the left, which acted freely; vision with the right eye misty. The skin was cooler than natural; pulse remarkably soft and compressible; the tongue clean; and an obvious anxious demeanour of the countenance; no headache. He stated that the affection came on suddenly a short time ago; that be had before the attack been in the habit of living, for some considerable period, rather "below par," abstaining from stimulating drinks, and engaging at the same time in his ordinary occupations, without sufficient relaxation. He was ordered to take a generous diet, and to apply a blister to the neck; twelve grains of scammony and calomel were also prescribed, every other night. In three days' time, after the free action of the purgative, a blister was applied to the forehead, and half a drachm of sesquioxide of iron ordered to be taken three times a day. The beneficial effect of this treatment was very striking, for in the course of a week the upper palpebra could be perfectly raised without effort; the diplopia was only occasional, and of objects more remote than on his first application. The mistiness of vision had also disappeared. The general state of the system had become much improved, and in another week or two the affected eye had regained its healthy condition.

PTOSIS OF THE LEFT UPPER EXELID, THE IRIS BEING UNAFFECTED.

CAsE 3.-W. B- aged fifty-eight, addicted to drinking, taking, however, wholesome diet also, became an out-patient, under Mr. Scott, Sept. 27 th. The upper palpebra dropped so as to leave exposed only a little more than the lower half of the cornea; the axis of the eye was directed to the left of the median line in the passive state of the organ; and when the internal rectus acted, the globe could not be turned inwards beyond that line, thus indicating partial palsy of that muscle; upper and lower rectus also in a similar condition. The pupil was in its natural state, but its action very sluggish. Single vision, most complete when the outer rectus of the affected eye acted; diplopia under almost every other dovement. There existed an inflamed condition of the conjunctiva, evidenced by lachrymation, increased on exposure to light; sensation of the presence of a foreign body, and agglutination of the tarsal margins in the morning. Features florid; tongue clean; pulse firm. He had no headache, but states that about a month ago he canght a severe cold, accompanied with intense cephalalgia, which was followed on the third morning by complete closure of the eyelid, with double vision. He was bled from the arm, and kept on low diet, and under this treatment he states that the head-symptoms disappeared, and slight power of raising the palpebra returned. The affection, however, in a short time became stationary, and he applied at the eye infirmary for further relief. Counter-irritation with cantharides plaster, followed by ceratum sabinæ, was employed. He was ordered to take-Sulphate of soda, half an ounce occasionally in the morning, and calomel, two grains; opium, a quarter of a grain every second hour.

On his second application, on the 15 th Dec., he was under mercurial influence, but saw no better. He was ordered to take the pill every night. This was sufficient to keep up mercurial action, and on Jan. 12th, he could raise the upper eyelid so as to uneover 